Western Washington University Western CEDAR

2014

\title{
A Squeeze for Two Common Sequences that Converge to e
}

Branko Ćurgus

Western Washington University, branko.curgus@wwu.edu

Follow this and additional works at: https://cedar.wwu.edu/math_facpubs

Part of the Mathematics Commons

\section{Recommended Citation}

Ćurgus, Branko, "A Squeeze for Two Common Sequences that Converge to e" (2014). Mathematics. 62. https://cedar.wwu.edu/math_facpubs/62

This Article is brought to you for free and open access by the College of Science and Engineering at Western CEDAR. It has been accepted for inclusion in Mathematics by an authorized administrator of Western CEDAR. For more information, please contact westerncedar@wwu.edu. 


\section{A Squeeze for Two Common Sequences That Converge to $e$}

Branko Curgus (curgus@wwu.edu), Western Washington University, Bellingham WA

The following two sequences are commonly used to define the number $e$ :

$$
S_{n}=\sum_{k=0}^{n} \frac{1}{k !} \quad \text { and } \quad P_{n}=\left(1+\frac{1}{n}\right)^{n}, \quad n \in \mathbb{N} \text { (positive integers). }
$$

In this note, we give a direct proof that $\left\{S_{n}\right\}$ and $\left\{P_{n}\right\}$ converge to the same limit. The main tool in our proof is the squeeze theorem, which is probably the easiest to prove among the limit theorems. However, to use it, we need to establish a relevant squeeze, which is the main result of this note.

Surprisingly, many elementary mathematical analysis textbooks do not include a proof that $\left\{S_{n}\right\}$ and $\left\{P_{n}\right\}$ converge to the same limit. The proofs in the classical book [4, Thm. 3.31] and in more recent [1, Prop. 3.3.1] and [3, App. 2] all use a limit theorem that they do not prove.

For completeness, we give the standard proof that $\left\{S_{n}\right\}$ is bounded above by 3 . Clearly, $S_{1}=2<3$ and as $1 / k ! \leq 1 /((k-1) k)$ for all $k>1$, we have

$$
S_{n}=\sum_{k=0}^{n} \frac{1}{k !}<2+\sum_{k=2}^{n}\left(\frac{1}{k-1}-\frac{1}{k}\right)=3-\frac{1}{n} .
$$

Thus, $S_{n}<3$ for all $n \in \mathbb{N}$. Since $\left\{S_{n}\right\}$ is increasing, it converges by the monotone convergence theorem.

The squeeze. The squeeze that we mentioned earlier is

$$
S_{n}-\frac{3}{2 n} \leq P_{n} \leq S_{n} \quad \text { for all } n \in \mathbb{N} .
$$

Applying the squeeze theorem to (1) shows that $\left\{P_{n}\right\}$ converges to the same limit as $\left\{S_{n}\right\}$, namely $e$.

Proof. Since (1) is true for $n \leq 2$, consider $n>2$. Our proof of (1) is a succession of four steps, each suggesting the next one.

1. The binomial theorem yields an expanded expression for $P_{n}$ :

$$
P_{n}=\left(1+\frac{1}{n}\right)^{n}=\sum_{k=0}^{n} \frac{n !}{k !(n-k) !} \frac{1}{n^{k}}=1+1+\sum_{k=2}^{n} \frac{1}{k !} \frac{n !}{(n-k) ! n^{k}} .
$$

2. For $k \in\{2, \ldots, n\}$, we rewrite the coefficient with $1 / k$ ! in (2) as the product of $k-1$ factors:

$$
\frac{n !}{(n-k) ! n^{k}}=\frac{(n-1) \cdots(n-k+1)}{n^{k-1}}=\left(1-\frac{1}{n}\right) \cdots\left(1-\frac{k-1}{n}\right) .
$$

3. An upper bound for the product in (3) is clearly 1, so we look for its lower bound next. We proceed recursively. At each step, in some sense, we turn a product into a smaller sum.

http://dx.doi.org/10.4169/college.math.j.45.5.391

MSC: 97130 
For $k=2$ the product in (3) has only one term and clearly $(1-1 / n) \geq 1-1 / n$. For $k=3$, we expand the product and drop a positive term:

$$
\left(1-\frac{1}{n}\right)\left(1-\frac{2}{n}\right)=1-\frac{1+2}{n}+\frac{1 \cdot 2}{n}>1-\frac{1+2}{n} .
$$

For $k=4$, we multiply both sides above by $\left(1-\frac{3}{n}\right)$, expand the product on the right, and drop a positive term:

$$
\left(1-\frac{1}{n}\right)\left(1-\frac{2}{n}\right)\left(1-\frac{3}{n}\right)>\left(1-\frac{1+2}{n}\right)\left(1-\frac{3}{n}\right)>1-\frac{1+2+3}{n} .
$$

Repeating this process a total of $k-1$ times and, at the end, using the familiar formula $1+2+\cdots+(k-1)=(k-1) k / 2$ (whose history is given in [2]) yields

$$
\left(1-\frac{1}{n}\right)\left(1-\frac{2}{n}\right) \cdots\left(1-\frac{k-1}{n}\right)>1-\frac{1+\cdots+(k-1)}{n}=1-\frac{(k-1) k}{2 n} .
$$

In conclusion, for the product in (3) we have

$$
1-\frac{(k-1) k}{2 n}<\frac{n !}{n^{k}(n-k) !}<1 \quad \text { for all } k \in\{2, \ldots, n\}
$$

4. The inequalities in (4) are applied to the right-most expression in (2) to establish the inequalities for $P_{n}$ :

$$
1+1+\sum_{k=2}^{n} \frac{1}{k !}\left(1-\frac{(k-1) k}{2 n}\right)<P_{n}<1+1+\sum_{k=2}^{n} \frac{1}{k !} \cdot 1=S_{n} .
$$

A simplification of the left-hand side of (5) leads to

$$
\sum_{k=0}^{n} \frac{1}{k !}-\sum_{k=2}^{n} \frac{1}{k !} \frac{(k-1) k}{2 n}=S_{n}-\frac{1}{2 n} \sum_{k=2}^{n} \frac{1}{(k-2) !}=S_{n}-\frac{1}{2 n} S_{n-2} .
$$

Further, since $S_{n-2}<3$, we have

$$
S_{n}-\frac{1}{2 n} S_{n-2}>S_{n}-\frac{3}{2 n}
$$

Consequently, the left-hand side of (5) is greater than $S_{n}-3 /(2 n)$ and the squeeze is established.

\section{References}

1. K. R. Davidson, A. P. Donsing, Real Analysis and Applications: Theory in Practice. Springer, New York, 2010 .

2. B. Hayes, Gauss's day of reckoning, Amer. Scientist 94 (2006) 200-205, http://dx.doi.org/10.1511/ 2006.3.200.

3. E. Maor, $e$ : The Story of a Number, Princeton Univ. Press, Princeton NJ, 2009.

4. W. Rudin, Principles of Mathematical Analysis. Third edition. McGraw-Hill, New York, 1976. 